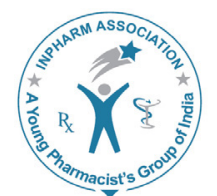

\title{
Correlation Study of Insulin Resistance and Essential Hypertension among Bangladeshi Male Volunteers
}

\author{
Susmita Sinha1, Qazi Shamima Akhter², Suman Banik², Mohammad Zakirul \\ Islam ${ }^{1}$, Mainul Haque ${ }^{4}$ \\ ${ }^{1}$ Eastern Medical College, Comilla-3250, Bangladesh. \\ ${ }^{2}$ Dhaka Medical College, Dhaka, Bangladesh. \\ ${ }^{3}$ National Institute of Cancer Research \& Hospital, Dhaka, Bangladesh. \\ ${ }^{4}$ Faculty of Medicine, University Sultan Zainal Abidin, Kampus Kota, Jalan Sultan Mahmud 20400 Kuala \\ Terengganu, Malaysia.
}

\begin{abstract}
Background: The patients with essential hypertension are increasing all over the world. There may be development of insulin resistance and hyperinsulinemia in essential hypertension. An association between essential hypertension and defective insulin secretion has been identified. Insulin resistance is the fundamental defect in the development of type 2 diabetes mellitus, hypertension and cardiovascular diseases. Objective: To observe the insulin resistance in adult male with essential hypertension. Methods: This is a cross sectional study was conducted in the Department of Physiology, Dhaka Medical College, Dhaka, Bangladesh from July 2012 to June 2013. A total number of 150 male subjects were selected with age ranging from 25-45 years. Seventy five male essential hypertensives were enrolled from Out- patient Department of Medicine, Dhaka Medical College Hospital, Dhaka. Otherwise healthy 75 of similar age were studied as control. Insulin resistance was assessed by HOMA-IR method. Fasting serum insulin level was measured by ELISA and fasting blood glucose by glucose oxidase method. Unpaired Student's ' $t$ ' and Pearson's correlation coefficient ( $r$ ) tests were performed for statistical analyses. Results: Current study reveals that essential hypertension has positive and significant relationship with fasting serum insulin level and insulin resistance. Conclusion: Incidence of insulin resistance is higher in essential hypertensive subjects in comparison to the control subjects. More in-depth prospective research is advocated to find remedies for common Bangladeshi patients.
\end{abstract}

Key words: Essential hypertension, Fasting serum insulin level, Insulin resistance.

\section{INTRODUCTION}

\begin{tabular}{|c|c|}
\hline \multicolumn{2}{|c|}{ Access this article online } \\
\hline Journal Sponsor & \multirow[b]{2}{*}{$\begin{array}{l}\text { Website: } \\
\text { www.jyoungpharm.org }\end{array}$} \\
\hline & \\
\hline www.phe & $\begin{array}{l}\text { DOI: } \\
\text { 10.5530/jyp.2015.3.10 }\end{array}$ \\
\hline
\end{tabular}

Hypertension is a recognized modifiable risk factor of cardiovascular disease (CVD), stroke and end stage renal disease. The prevalence of hypertension has increased in young men than in women. ${ }^{1}$ Patients with arterial hypertension and no definable cause are said to have primary, essential or idiopathic hypertension. ${ }^{2}$ Bangladesh Non-communicable Disease (NCD) Risk Factor Survey

\footnotetext{
*Address for correspondence:

Dr Mainul Haque, Professor and Head of the Unit of Pharmacology, Faculty of Medicine, University Sultan Zainal Kampus Kota, Jalan Sultan Mahmud 20400 Kuala Terengganu, Malaysia.E-mail : runurono@gmail.com
} 

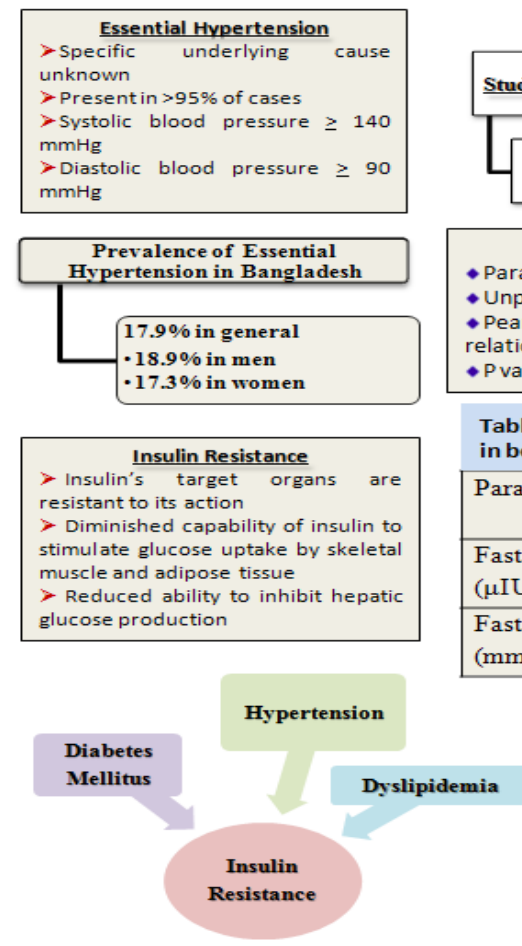

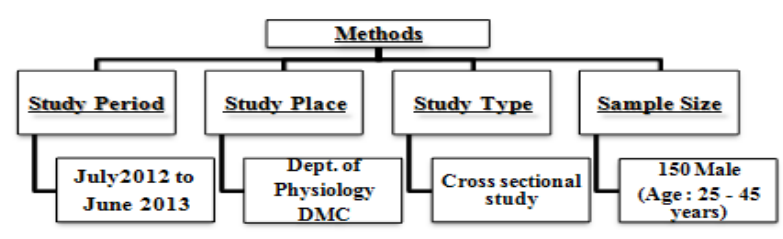

\section{StatisticalAnalysis}

- Parametric variables were expressed as mean \pm SD

- Unpaired Students ' $t$ ' test was done to compare between the groups.

- Pearson's correlation coefficient (r) test was done to compare relationship between the parameters

-P value $<0.05$ was taken as level of significance.

Table : Fasting serum insulin level and fasting blood glucose level in both groups $(n=150)$

\begin{tabular}{|l|c|c|}
\hline Parameter & $\begin{array}{c}\text { Control } \\
(\mathrm{n}=75)\end{array}$ & $\begin{array}{c}\text { Hypertensive } \\
\text { patients }(\mathrm{n}=75)\end{array}$ \\
\hline $\begin{array}{l}\text { Fasting serum in sulin level } \\
(\mu \mathrm{IU} / \mathrm{ml})\end{array}$ & $10.05 \pm 4.45$ & $21.11 \pm 9.18^{*}$ \\
\hline $\begin{array}{l}\text { Fasting blood glucose level } \\
(\mathrm{mmol} / \mathrm{L})\end{array}$ & $5.07 \pm 0.56$ & $5.37 \pm 0.59$ \\
\hline
\end{tabular}

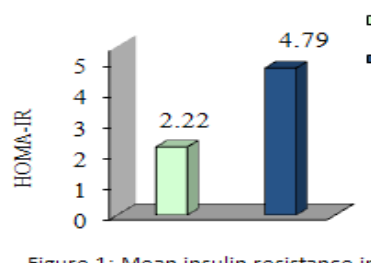

口Group A (Healthy) -Group B (Essential hypertension)

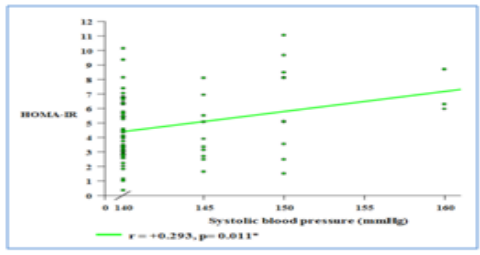

Figure 2: Correlation between systolic blood pressure and HOMA-IR in study group $(n=75)$

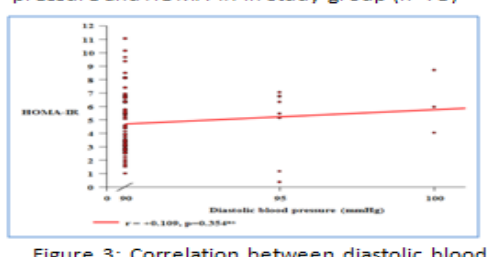

Figure 3: Correlation between diastolic blood pressure and HOMA-IR in study group $(n=75)$

\section{In This Study:}

-The mean value of HOMA-IR was significantly higher in adult male with essential hypertension when compared with that of controls.

-Systolic blood pressure and diastolic blood pressure show positive correlation with HOMA-IR but was significant only with systolic blood pressure.

\section{Conclusion}

Incidence of insulin resistance is higher in essential hypertensive subjects in comparison to the control subjects.

\section{Figure 1: Mean insulin resistance in both} groups $(n=150)$

\section{Graphical Abstract}

2010 was carried out by Bangladesh Society of Medicine in collaboration with Directorate General of Health Services (DGHS) and WHO in adults aged $\geq 25$ years. According to the survey, prevalence of hypertension is $17.9 \%$ in general, $18.5 \%$ in men and $17.3 \%$ in women. ${ }^{3}$

Pathogenesis of essential hypertension is not clearly understood. Many factors may contribute to its development. Insulin resistance is one of these factors. There is interplay between environmental and genetic factors that contributes to the pathophysiology of essential hypertension. ${ }^{4}$ Insulin is the most potent anabolic hormone which is essential for appropriate tissue development, growth, and maintenance of whole body glucose homeostasis. ${ }^{5}$ Insulin resistance is the primary metabolic disorder in which there is a diminished ability of insulin to stimulate glucose uptake by skeletal muscle and adipose tissue. There is also reduction in insulin's ability to inhibit hepatic glucose production, so hepatic output of glucose increases. ${ }^{6}$

Studies have reported the relationship between elevated fasting serum insulin (FSI) level and various metabolic disorders including non-insulin dependent diabetes mellitus, dyslipidemia and hypertension. ${ }^{7}$ Elevated levels of FSI was found associated with increased risk of cardiovascular disease. ${ }^{8-10}$
In contrast, some investigators observed no significant difference between the healthy subjects and essential hypertensive patients with regard to insulin resistance. ${ }^{11,12}$ The precise nature of the relationship between FSI level and essential hypertension remains still obscure. Therefore, this study has been designed to assess the insulin resistance in adult male with essential hypertension.

\section{MATERIAL AND METHODS}

This is a cross sectional study conducted in the Department of Physiology, Dhaka Medical College (DMC), Dhaka, Bangladesh from July 2012 to June 2013. This study was approved by Ethical Review Committee of DMC Memo No DMC/Ethical/2013/17 Dated 13/02/2013. Seventy five male of $25-45$ years of age with essential hypertension participated in this study. They were selected from Outpatient Department of Medicine, Dhaka Medical College Hospital, Dhaka, Bangladesh. Otherwise healthy 75 of similar age were studied as control group for comparison. All the subjects were free from any endocrine disorder, renal disease, psychiatric disorder and any hereditary disease.

The objectives, nature, purpose and benefit of the study were explained to the subjects in details after selection of subjects. Informed written consent was taken from all 
Table 1: General Characteristics of the Subjects in Both Groups $(n=150)$

\begin{tabular}{ccc} 
Parameters & $\begin{array}{c}\text { Control } \\
(\mathrm{n}=75)\end{array}$ & $\begin{array}{c}\text { Hypertensive } \\
\text { patients }(\mathrm{n}=75)\end{array}$ \\
\hline Age $($ years $)$ & $33.53 \pm 6.78$ & $36.43 \pm 6.96$ \\
\hline Height $(\mathbf{c m})$ & $165.53 \pm 5.22$ & $164.67 \pm 5.21$ \\
\hline Weight $(\mathbf{k g})$ & $60.49 \pm 4.44$ & $61.40 \pm 3.47$ \\
BMI $\left(\mathbf{k g} / \mathbf{m}^{2}\right)$ & $22.11 \pm 1.75$ & $22.69 \pm 1.61$ \\
SBP $(\mathbf{m m H g})$ & $116.73 \pm 6.65$ & $142.08 \pm 5.02^{*}$ \\
DBP $(\mathbf{m m H g})$ & $73.47 \pm 4.93$ & $90.93 \pm 2.42^{*}$
\end{tabular}

Data were expressed as Mean \pm SD. Unpaired Student's 't' test was performed to compare between groups. ${ }^{*}=$ Significant at $\mathrm{P}<0.001$

\begin{tabular}{ccc}
$\begin{array}{c}\text { Table 2: FSI Level and FBG Level in Both Groups }(\mathrm{n}=150) \\
\text { Parameter }\end{array}$ & $\begin{array}{c}\text { Control } \\
(\mathrm{n}=75)\end{array}$ & $\begin{array}{c}\text { Hypertensive } \\
\text { patients }(\mathrm{n}=75)\end{array}$ \\
$\begin{array}{c}\text { FSI level } \\
(\mu \mathrm{lU} / \mathrm{ml})\end{array}$ & $10.05 \pm 4.45$ & $21.11 \pm 9.18^{*}$ \\
$\begin{array}{c}\text { FBG level } \\
(\mathrm{mmol} / \mathrm{L})\end{array}$ & $5.07 \pm 0.56$ & $5.37 \pm 0.59$ \\
\hline
\end{tabular}

Data were expressed as Mean \pm SD. Unpaired Student's 't' test was performed to compare between groups. ${ }^{*}=$ Significant at $\mathrm{P}<0.001$

the participants. The subjects were advised to attend the laboratory in the Department of Physiology of DMC between 8-10 AM. Detail personal history, drug history, past medical history, all clinical examinations were done. Then anthropometric measurement including height, weight and BMI were taken. Five $\mathrm{ml}$ blood from all subjects was collected after an overnight fast (at least 12 hours). All the information was recorded in a data schedule.

FSI level was assessed by Enzyme Linked Immunosorbent Assay (ELISA), Serum total cholesterol; HDL cholesterol and triglyceride were measured by automated fully enzymatic colorimetric method. The LDL cholesterol level in serum was calculated by using the Friedewald formula. Fasting blood glucose (FBG) level was estimated by glucose

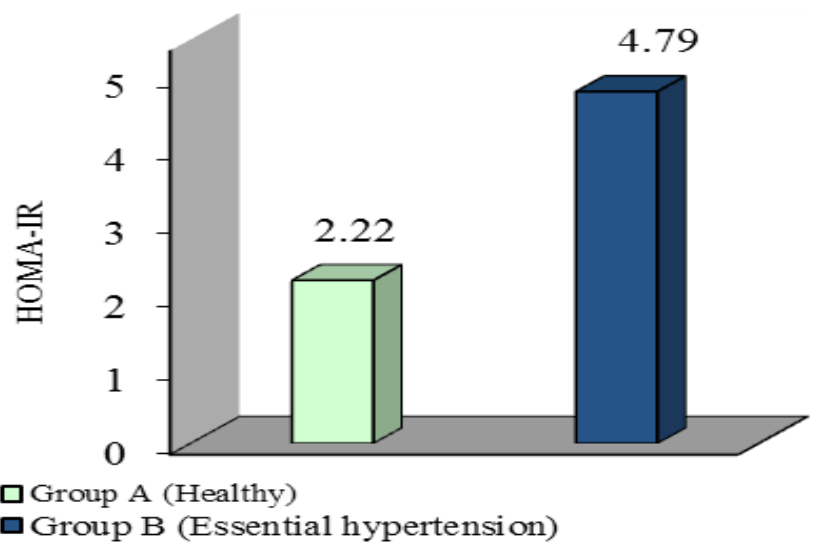

Figure 1: Mean Insulin Resistance in Both Groups ( $n=150)$ oxidase method in the laboratory of Department of Physiology and Molecular Biology, BIRDEM (popularly know as Diabetic Hospital) Academy, Dhaka. The "gold standard" technique for the evaluation of insulin resistance is the euglycemic-hyperinsulinemic clamp. But the homeostasis model assessment of insulin resistance index now-a-days can be considered the best non-invasive surrogate marker of insulin resistance. Insulin resistance was calculated as [Fasting insulin $(\mu \mathrm{IU} / \mathrm{ml}) \mathrm{x}$ fasting glucose $(\mathrm{mmol} / \mathrm{L}) / 22.5] .{ }^{13}$ Data were expressed as mean and standard deviation (SD). For statistical analyses, unpaired Student's ' $\mathrm{t}$ ' and Pearson's correlation coefficient ( $\mathrm{r}$ ) tests were used. All data were analyzed by SPSS 13.5 version.

\section{RESULTS}

General characteristics of the subjects are presented in (Table 1). Systolic and diastolic blood pressures were higher in hypertensive patients. FBG level was almost similar in both essential hypertensive patients and controls. The mean $( \pm$ SD) FSI level in hypertensive patients was higher than that of controls, which was statistically highly significant $(\mathrm{p}<0.001)$ (Table 2). Mean HOMA-IR was significantly higher in Hypertensive group than that of the control group (Figure 1). Mean lipid profile was higher in hypertensive group than that of the control group which was statistically not significant (Figure 2). Correlation analysis between HOMA- IR and both systolic and diastolic blood pressure shows positive correlation in hypertensive patients but it was statistically significant for systolic blood pressure only. But there was almost no correlation between these two parameters in control subjects (Figure 3 and 4). In addition almost no correlation was found between glucose level and fasting insulin level in both hypertensive and control subjects (Figure 5).

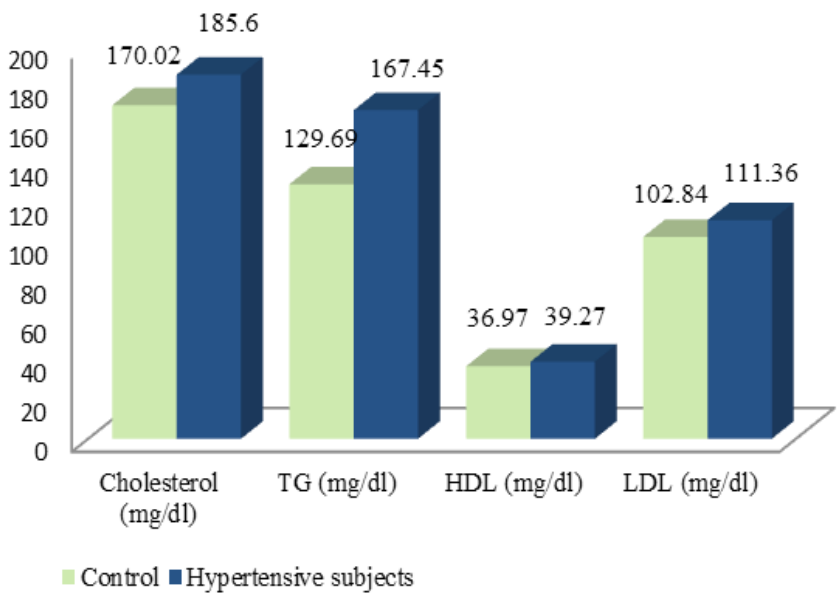

Figure 2: Mean Lipid Profile in Both Groups $(n=150)$

Journal of Young Pharmacists Vol $7 \bullet$ Issue $3 \bullet$ Jul-Sep 2015 


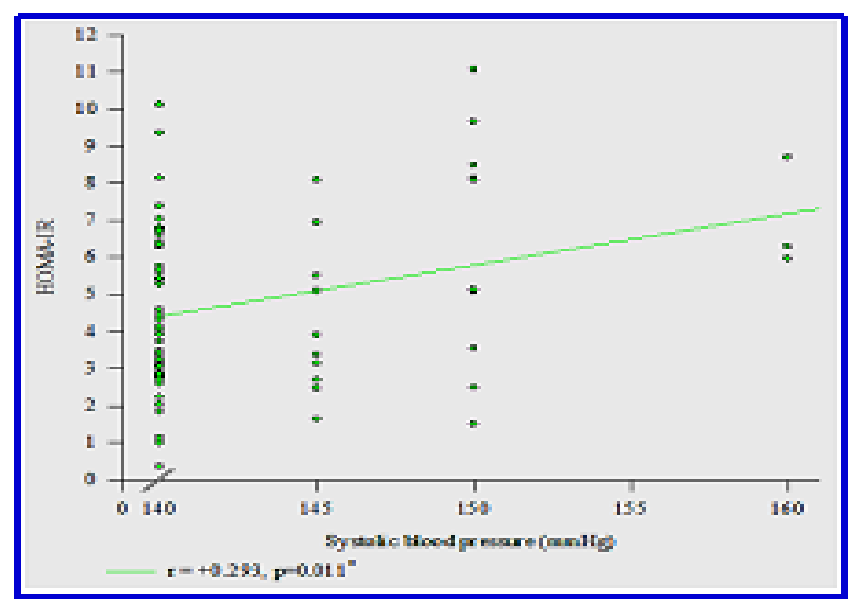

Figure 3: Correlation between Systolic Blood Pressure and HOMA-IR in Study Group ( $n=75$ )

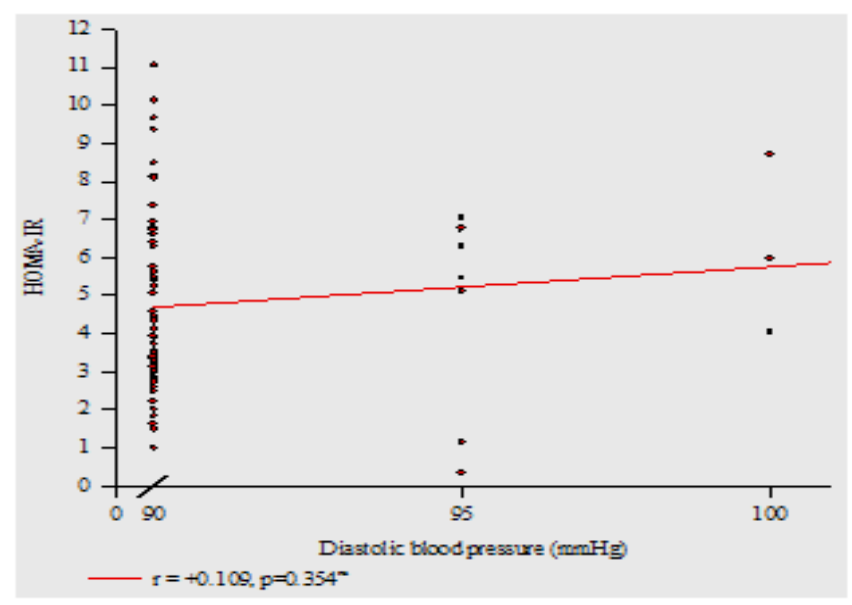

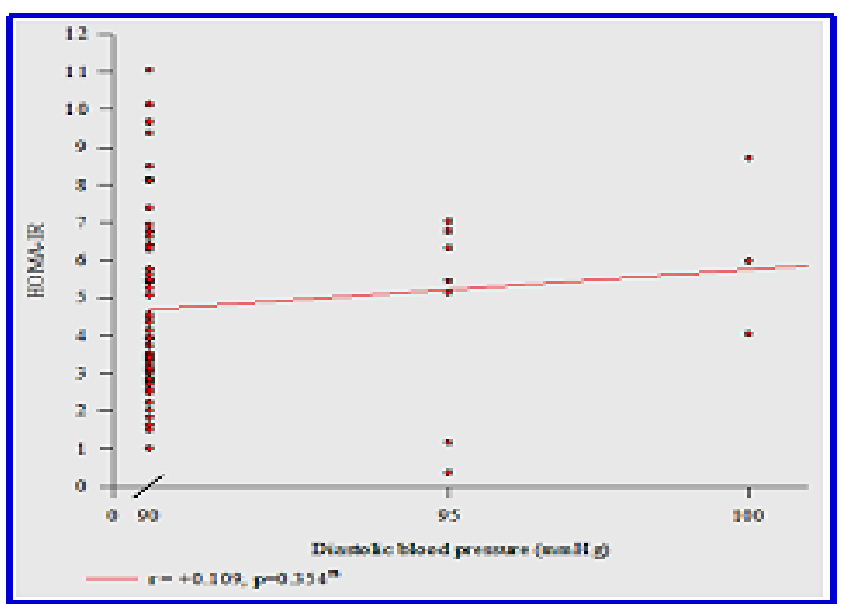

Figure 4: Correlation between Diastolic Blood Pressure and HOMA-IR in Study Group ( $n=75)$

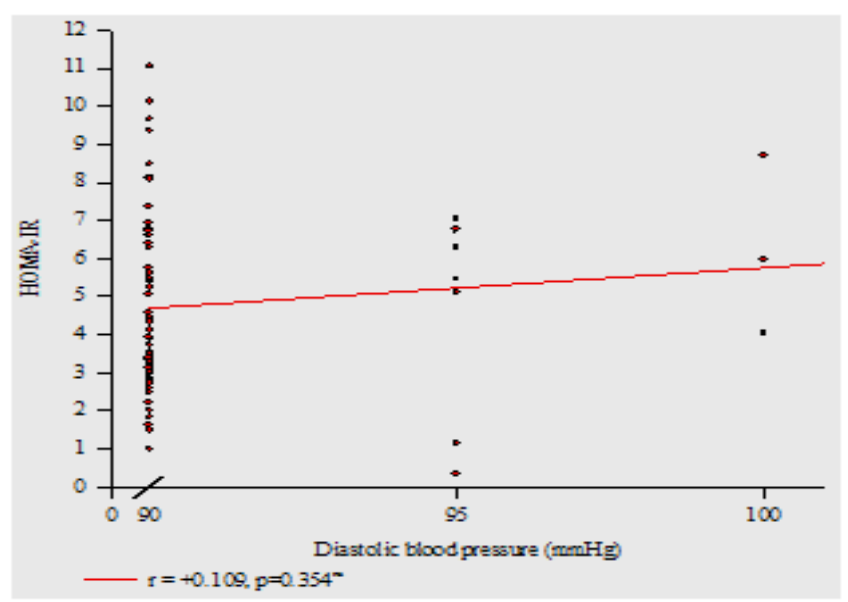

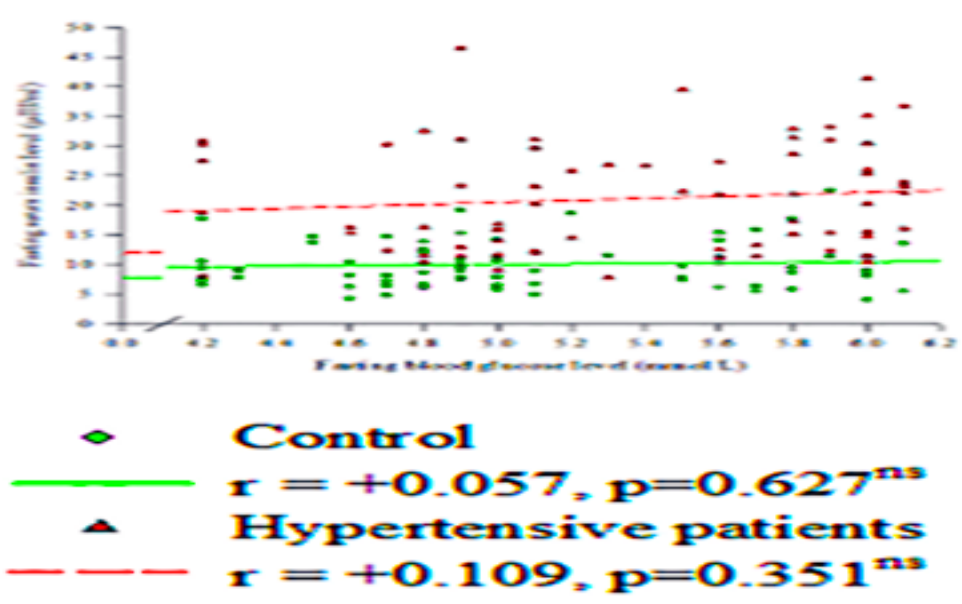

Figure 5: Correlation between FBG Level and Fasting Insulin Level in Control $(n=75)$ and in Hypertensive Patients ( $n=75)$ 


\section{DISCUSSION}

In the present study, FSI level in control was almost within normal range and also similar to those reported by the various investigators from different countries. ${ }^{7-10}$ The mean value of HOMA-IR was significantly higher in adult male with essential hypertension when compared with that of controls. Systolic blood pressure and diastolic blood pressure show positive correlation with HOMA-IR but was significant only with systolic blood pressure. This finding is consistent with the findings of some other investigators of other countries. ${ }^{7-10,12}$

Elevated insulin level may alter blood pressure as it has effects on the sympathetic nervous system and renal sodium reabsorption. It has been suggested that sympathetic over activity may lead to structural changes in the microvasculature, which ultimately increases blood pressure and decreases peripheral glucose uptake. ${ }^{7-10}$ Again, essential hypertensive subjects have significant defect in activating the insulin receptor. There is decreased insulin action on insulin receptor (IR) which reduces the activation of receptor tyrosine kinase. As a result, decrease in receptor Autophosphorylation and tyrosine phosphorylation of IRS-1. Also, there is decrease in activation of phosphatidyl inositol (PI) 3- kinase, a subunit of IRS-1. This IRS-1 cause's decrease glucose transport to skeletal muscles. ${ }^{14}$

In the present study, FSI level is increased in adult male subjects with essential hypertension and essential hypertension has positive correlation with FSI level. No correlation was found between insulin level and blood pressure in the control subjects. This finding supports the relationship between insulin level and elevated blood pressure in hypertensive subjects which may be linked to the defective mechanism in insulin secretion. But the exact mechanism is not elucidated as the insulin receptor activity and serum catecholamines level were not assessed in the study. This is a cross-sectional study with its own limitation. Therefore, this only snap shot of the miseries of Bangladeshi hypertensive subjects.

\section{CONCLUSION}

Correlation analysis between HOMA- IR and both systolic and diastolic blood pressure shows positive correlation in hypertensive patients but it was statistically significant for systolic blood pressure only. Therefore, the current study concludes that Incidence of insulin resistance is higher in essential hypertensive subjects in comparison to the control subjects. More in-depth prospective research is advocated to find remedies for common Bangladeshi patients.

\section{CONFLICT OF INTEREST}

Authors possess no conflicts of interest.

\section{ACKNOWLEDGEMENT}

Researchers are grateful to those patients who participated in the study This research obtains no funding.

\section{Highlights of Paper}

- The mean value of HOMA-IR was significantly higher in adult male with essential hypertension when compared with that of controls.

- Systolic blood pressure and diastolic blood pressure show positive correlation with HOMA-IR but was significant only with systolic blood pressure.

- The relationship between insulin level and elevated blood pressure in hypertensive subjects may be linked to the defective mechanism in insulin secretion.

\section{Author Profile}

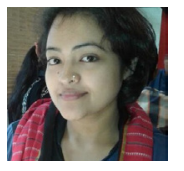

Susmita Sinha is an Assistant Professor at the Department of Physiology, Eastern Medical College, Comilla, Bangladesh. She is a young researcher and teacher in the field of Physiology and also a member of Bangladesh Society of Physiologists (BSP). 


\section{REFERENCES}

1. Kearney PM, Whelton M, Reynolds K, Whelton PK, He J. Global burden of hypertension: analysis of world-wide data. Lancet 2005; 365(9455): 217-23.

2. Boon NA, Colledge NR, Walker BR, Hunter JAA. Davidson's Principles and Practice of Medicine. 20th ed. India: Elsevier Limited; 2006.

3. Uddin MN, Ali MZ, Jahan NWB, Rashid MA, Sultan MK, Hoque MA, et al. Study of serum insulin level in hypertensive patients. Cardiovasc J. 2011; 4(1): 13-6.

4. Islam AKM, Majumder AAS. Hypertension in Bangladesh-a review. Indian Heart J. 2012; 64(03): 323.

5. Pessin JH, Saltiel AR. Signaling pathways in insulin action: molecular targets of insulin resistance. J Clin Invest. 2000; 106(2): 165- 9.

6. Chiarelli F, Marcovecchio ML. Insulin resistance and obesity in childhood. Eur J Endocrinol. 2008; 159(1): 567-74.

7. Haffner SM, Valdez RA, Hazuda HP, Mitchell BD, Morales PA, Stern MP. Prospective analysis of the insulin-resistance syndrome (syndrome X). Diabetes 1992; 41(6): 715-22.

8. Welborn TA, Breckenridge A, Dollery CT, Fraser TR. Seruminsulin in essential hypertension and in peripheral vascular disease. Lancet 1966; 1(7451): 1336-7.

9. Penesova A, Cizamarova E, Belan V, Blazicek P, Imrich R, Vlcek $M$, et al. Insulin resistance in young, lean male subjects with essential hypertension. J Hum Hypertens. 2011; 25(6): 391-400.

10. Kronenberg F, Rich SS, Sholinsky P, Arnett DK, Province ME, Myers $\mathrm{RH}$, et al. Insulin and hypertension in the NHLBI family heart study. Am J Hypertens. 2000; 13(3): 240-50.

11. Baba T, Kodama T, Tomiyama T, Fujita N, Takebe K. Hyperinsulinemia and blood pressure in non-obese middle-aged subjects with normal glucose tolerance. Tohoku J Exp Med. 1991; 165(3): 229-35.

12. Every NR, Boyko EJ, Keane EM, Marshall JA, Rewers M, Hamman RF. Blood pressure, insulin, and C-peptide levels in San Luis Valley, Colorado. Diabetes Care 1993; 16(12): 1543-50.

13. Matthews DR, Hosker JP, Rudenskin AS, Naylor BA, Treacher DF, Turner RC. Homeostasis model assessment: insulin resistance and beta-cell function from fasting plasma glucose and insulin concentrations in man. Dibetologia 1985; 28(7): 412-9.

14. Sloniger JA, Saengsirisuwan V, Diehl CJ, Dokken BB, Lailerd $\mathrm{N}$, Lemieux AM, et al. Defective insulin signaling in skeletal muscle of the hypertensive TG (mREN2) 27 rat. Am J Physiol Endocrinol Metab. 2005; 288(6): E1074-81. 